\title{
TYPOLOGI KERUSAKAN MASONRY INFILLED FRAME
}

\author{
Marwahyudi ${ }^{1)}$ \\ ${ }^{1)}$ GFY Research Group USS Jl. Adisucipto, No.154, Jajar, Surakarta;. Email: yudhiedesign@gmail.com
}

\begin{abstract}
Abstrak
Manusia membangan gedung dipergunakan untuk berteduh, istirahat, berinteraksi. Elemen-elemen gedung bergabung menyusun bangunan. Elemen saling mengikat satu dengan yang lainnya. Ikatan tersebut memperkuat banguanan dalam mererima gaya. Elemen bangunan terdiri dari pondasi, kolom, balok, dinding, atap, kuda-kuda, genting. Dinding batu bata tersusun dari elemen batu bata dan mortar yang bersifat homogen. Dinding mempunyai karateristik dalam menahan gaya, yaitu saling mendukung dan memperkuat dalam ikatan. Dinding rumah tinggal merupakan bagian yang menyokong bangunan sehingga menjadi elemen penting unyuk diteliti. Penelitian ini menganalisis typologi kerusakan yang terjadi pada dinding batu bata. Typologi kerusakan dianalisis dari hasil uji geser di laboratorium. Titik awal kontak pada daerah lebar dan panjang yang menahan dapat diamati dariprilaku uji geser. Jarak tepi sampai pada titik kontak awal disebut panjang kontak (Zw). Luas daerah kontak ditentukan oleh panjang kontak dan tebal panel dinding batu bata. Lebar strut's (bw) dihasilkan dari metode matematis dengan parameter panjang kontak (panjang dan lebar panel batu bata). Lebar strut's berpengaruh terhadap luas daerah kontak. Typologi, arah kerusakan diperoleh dari analisis benda uji dan validasi lapangan.
\end{abstract}

Kata kunci: Typologi, panjang kontak (Zw), lebar strut's (bw).

\begin{abstract}
Humans build buildings used to shelter, rest, interact. The elements of the building joined to compose the building. Elements bind to one another. The bond strengthens the building in accepting style. The building elements consist of foundations, columns, beams, walls, roofs. Masonry walls are composed of homogeneous brick and mortar elements. It's have characteristics in resisting force, namely supporting each other and strengthening in bonding. The residential masonry walls are the parts that support the building so that it becomes an important element to be researched. This research analyzes the typology of damage that occurs in brick walls. The damage typology was analyzed from the results of the shear test in the laboratory. Initial of contact in the area of the width and length that it holds can be observed from the shear test behavior. The edge distance to the initial contact point is called the contact length $(\mathrm{Zw})$. The area of contact area is determined by the contact length and thickness of the brick wall panels. Strut width $(b w)$ is generated from mathematical methods with contact length parameters (length and width of the brick panel). Strut width affects the area of contact. Typology, direction of damage obtained from analysis of test objects and field validation.
\end{abstract}

Keywords: Typology, contact length ( $Z w)$, width of strut's (bw)..

\section{PENDAhULUAN}

Bangunan di Indonesia kebanyakan menggunakan dinding batu bata. Batu bata mempunyai sifat yang unik dibandingkan dengan elemen bangunan lainnya. Keunikan ini yang menarik untuk di observasi dan analisis agar semua yang ada pada dinding batu bata ini bisa diketahui dan di optimasikan kemampuannya.

Kemampuan dinding batu bata dalam menahan gaya di pengaruhi oleh material penyusun dinding batu bata (Miha Timocevic, 2006). Semakin bagus kualitas penyusun maka semakin tinggi kemampuan menahan gaya yang bekerja. Semakin tinggi kemampuan menahan gaya akan berkorelasi dengan kemampuan ikat dan lekat antar batu bata dengan mortar. Kemampuan ikat dan lekat batu bata juga dipengaruhi oleh model batu bata (Marwahyudi, 2014). Maka Kekuatan batu bata dipengaruhi oleh kualitas material penyusun, daya lekat mortar dan model batu bata.

Kualitas bahan, daya lekat dan model batu bata akan mempengaruhi model kerusakan dari dinding batu bata. Penelitian ini meneliti tentang typologi kerusakan batu bata dengan uji geser pada skala laboratorium. Hasil skala laboratorium akan di validasikan dengan gambar kerusakan akibat gempa. 
Kerusakan yang terjadi saat pengujian geser diamati daerah awal retakan, pola retakan dan menentukan daerah kontak. Hasil dari pengamatan kerusakan saat pengujian laboratorium dianalisis untuk mendapatkan kebaharuan. Kebahuruan yang diperoleh adalah panjang kontak untuk model batu bata Indonesia.

\section{METODE}

\section{Bahan dan Alat}

Agar mendapatkan hasil yang sesuai dengan kondisi lapangan maka, bahan dan alat yang digunakan adalah: Batu bata lokal (dari desa pendem wetan Karanganyar), Semen menggunakan produk Indonesia PPC, Pasir menggunakan pasir merapi yang di ambil dari kali gendol, air yang digunakan dari sumber air tanah dilokasi laboratorium. Sedangkan alat uji menggunakan Compression Test Mechine.

\section{Metode penelitian}

Penelitian mengunakan metode destruktif dengan beberapa benda uji. Benda uji panel batu bata berukuran $30 \times 30 \mathrm{~cm}$ dengan campuran mortar $1: 10$. Panel batu bata diuji geser dengan memperhatikan pola retakan yang terjadi. Titik titik awal keretakan di amati dan di analisis guna menentukan typologi kerusakan yang terjadi

Model pengujian seperti pada gambar di bawah ini.

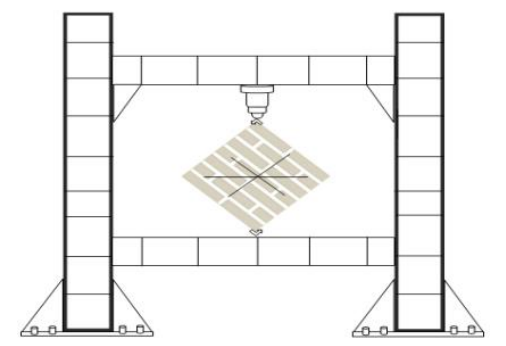

Gambar 1. Model Pengujian

Set up uji laboratorium akan diperoleh pola kerusakan yang terjadi. Pola kerusakan berdasarkan kemampuan menahan gaya dan dimulai dari daerah yang lemah. Contoh pola kerusakan dan parameter yang terjadi saat pembebanan diilustrasikan pada gambar 2 .

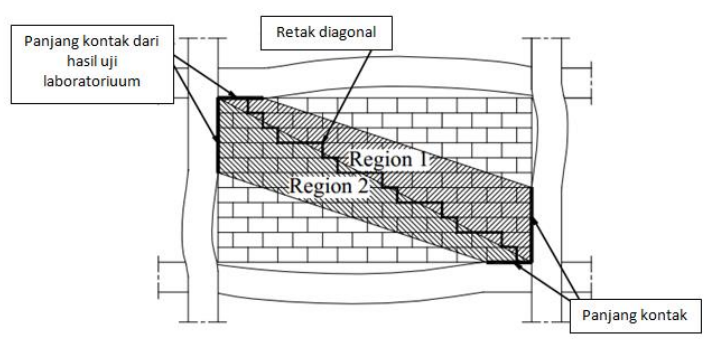

Gambar 2. Ilustrasi Saat Pembebanan (Well W. El-Dakhakhni, 2003)

Hasil pola kerusakan akan terlihat berapa nilai baru. Nilai baru yang terjadi tergantung dari kualitas bahan batu bata dan mortar. Kekuatan dinding batu bata diinterpretasikan oleh luasan daerah kontak langsung saat menerima gaya (Francisco J. Crisafulli, 1997). Semakan luas daerah kontak maka semakin kuat dinding batu bata tersebut. kontak dan panjang kontak saat menerima beban. Luasan daerah kontak membentuk bidang persegi panjang dan dihitung bersarkan parameter yang diperoleh. Parameter yang diperoleh sangat terpengaruh oleh mutu bahan.

Kebaharuan dan bentuk daerah kontak dapat digambarkan pada gambar 3 .

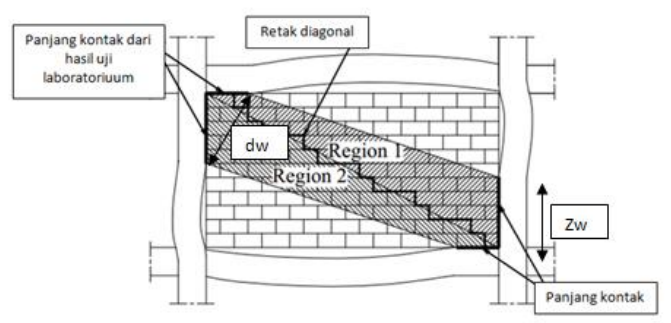

Gambar 3. Kebaharuan nilai dw dan Zw

Kekuatan batu bata dapat dihitung menggunakan rumus (ASTM, 2005):

$$
\begin{gathered}
\mathrm{T}=\frac{0.707 x P}{A n} \\
A n=\frac{(w+h)}{2} t . n
\end{gathered}
$$

Beberapa pola kerusakan yang ada pada dinding batu bata: kerusakan sudut, kerusakan diagonal, kerusakan pusat, kerusakan pada siar diagonal, kerusakan siar horizontal dan kerusakan siar vertikal (Priestley \& Paulay, 1992) 
Retak adalah kerusakan yang dominan terdapat pada dinding batu bata. Semua dinding batu bata mengalami kerusakan tersebut. Kerusakan ini bisa terlihat oleh visual maupun tidak tergantung dari besar keretakannya. Kerusakan retak minimal terjadi pada daerah bukaan, yaitu pada kusen pentu maupun jendela (Taylor, 2001).

\section{HASIL DAN PEMBAHASAN}

Hasil penelitian menunjukan kerusakan yang terjadi pada dinding mempunyai pola berbeda sesuai dengan kekuatan dari dinding batu bata. Keretakan dimulai dari daerah yang menerima beban yaitu daerah kontak.

Nilai panjang kontak ditandai dengan awal retakan. Adapun panjang kontak pada beberapa benda uji adalah:
a. $\quad \mathbf{6 0 \%}$ benda uji dengan panjang kontak 0,351
b. $\mathbf{1 2 \%}$ benda uji dengan panjang kontak 0-0,1 1
c. $\mathbf{2 8 \%}$ benda uji dengan panjang kontak 0, 1-0,2 I

Nilai-nilai diatas merupakan letak titik awal panel batu bata mengalami retakan. Retakan akan mengalir dari titik awal retakan menuju daerah yang lemah sampai pada membelah panel. Daerah yang lemah biasanya terdapat pada sambungan batu bata dengan mortar. Seperti pada gambar 4 dan 5

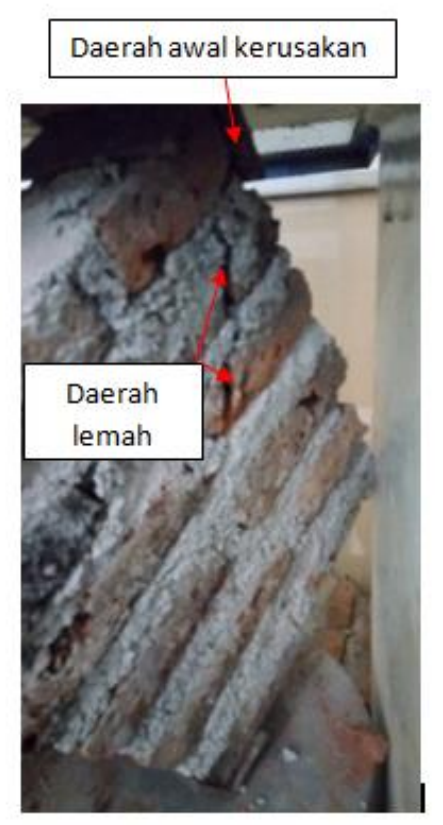

Gambar 4. Awal Keretakan Saat Pengujian

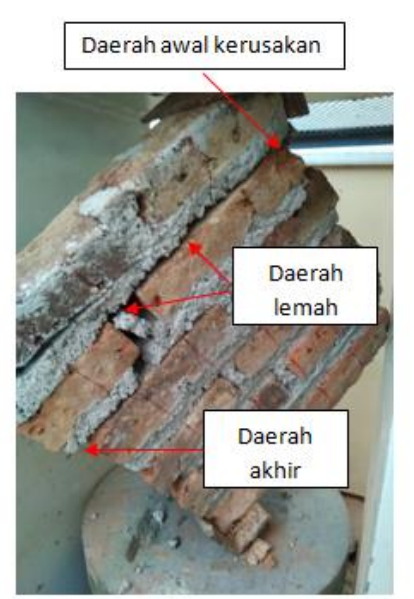

Gambar 5. Awal Keretakan Akhir Saat Pengujian

Pada gambar keretakan diatas terlihat kerusakan diawali daerah yang tidak mampu menahan gaya, kemudian menuju daerah lemah dan terakhir menuju keluar luar yang mengakibatkan kerusakan. Kerusakan bangunan diakibatkan kitidakmampuan menahan gaya, gaya yang bekerja meliputi gaya tekan tarik dan geser. Kerusakan yang ada dari retak sampai pada keruntuhan bangunan (Massimiliano Lucchesi, 2008).

Hasil panjang kontak (Zw) dinding batu bata terdapat dua daerah yaitu panjang dan lebar, setelah ke dua daerah ditemukan nilai panjang kontak maka diperoleh nilai bw. Mencari panjang bw menggnakan perhitungan matematis sederhana dengan memperhatikan parameter $\mathbf{Z w}$ pajang dan $\mathbf{Z w}$ lebar.

Berdasarkan hasil analisis matematis benda uji makadiperoleh nilai $\mathbf{Z w}$ dan bw sebagai berikut.

$$
\begin{gathered}
Z w=0,2 ~ \\
b w=0,21-0,25 \mathrm{dw}
\end{gathered}
$$

Beberapa ilmuan terdahulu menentukan nilai bw. Nilai bw tersebut berdasar uji laboratorium dengan menggunakan kualitas bahan sesuai dengan negaranya. Adapun nilai bw adalah sebagai berikut:

$$
\begin{aligned}
& \mathrm{bw}=0,175\left((\lambda \mathrm{h})^{-0,4} \mathrm{dw}\right. \text { (Turkey, 2001) } \\
& \mathrm{bw}=0,33 \mathrm{dw}(\text { Barkanov, 1978) } \\
& \mathrm{bw}=0,16\left((\lambda \mathrm{h})^{-0,3} \mathrm{dw}\right. \text { (Mainstone) (Crisafulli, } \\
& 1997)
\end{aligned}
$$

bw $=0,25 \mathrm{dw}$ (Priestley \& Paulay, 1992) 


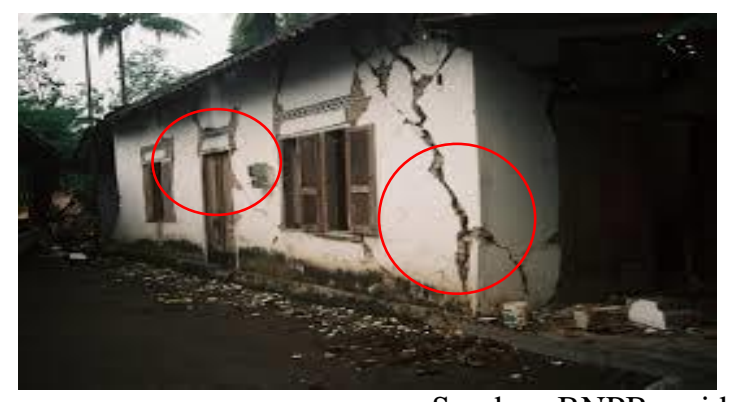

Sumber: BNPB.go.id

Gambar 6.: Gambar Kerusakan Akibat Gempa Bumi tahun 2016.

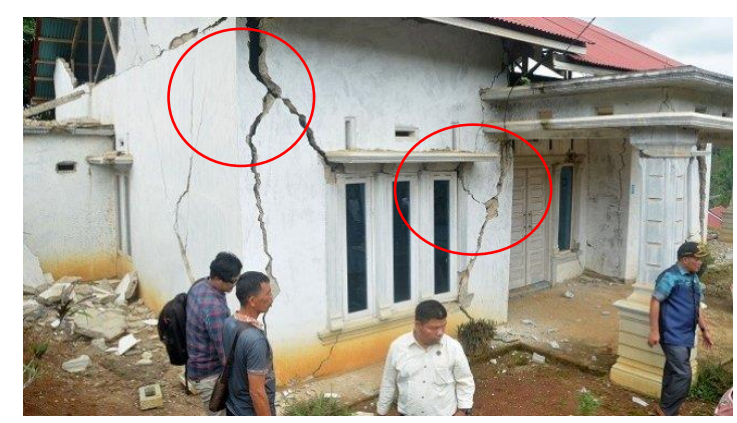

Sumber: BNPB.go.id

Gambar 7: Gambar Kerusakan Akibat Gempa Bumi tahun 2019

Dari gambar benda uji dan kerusakan akibat gempa typologi kerusakannya sama. Berdasarkan hal tersebut maka sekala laboratorium dapat menjadikan acuan analisis dalam menentukan prediksi kejadian dilapangan.

\section{SIMPULAN}

Hasil dari penelitian adalah sebagai berikut:

1. Rata-rata panjang kontak adalah $(\mathbf{Z w}=$ 0,2 l) 0,21 dari panjang,

2. Mempunyai lebar strut's $\mathbf{b w}=\mathbf{0 , 2 1 -}$ $0,25 \mathrm{dw}$,

3. Kerusakan atau retak mulai dari daerah terpapar gaya menuju ke daerah lemah selanjutnya sampai pada merusak menjadi bagian-bagian berdasarkan jalur retak yang ada,

4. Retak paling banyak pada daerah sambungan antara batu bata dan mortar,

5. Metode strut's biasa digunakan untuk mengalisis kekuatan dinding batu bata berdasarkan uji geser.

\section{UCAPAN TERIMAKASIH}

Terima kasih diucapkan kepada semua pihak yang telah membantu kelancaran penelitian ini. Tanpa adanya bantuan dari beberapa pihak terkait maka penelitian ini tidak akan. Ucapan terima kasih terkhusus kepada:

1. Kementrian Ristek Dikti,

2. Pemerintah daerah Karangganyar,

3. Kelompok mitra penggrajin batu bata di Pendem Wetan Karanganyar,

4. Laboratorium Universitas Sebelas Maret Surakarta,

5. Laboratorium beserta tim Universitas Veteran Bangun Nusantara Sukoharjo,

\section{DAFTAR PUSTAKA}

ASTM. (2005). Standard Test Method for Diagonal Tension (Shear) in Masonry Assemblages, ASTM E519-02. Annual Book of ASTM Standards, 92(June), 1-5.

Barkanov, E. (1978). Introduction to the finite element method. Studies in Mathematics and Its Applications, 4(C), 36-109. https://doi.org/10.1016/S01682024(08)70181-4

Crisafulli. (1997). Crisafulli-PHDThesis-1997.pdf.

Francisco J. Crisafulli. (1997). thesis_fulltext_masonry.pdf. Christchurch, New Zealand: University of Canterbury.

Marwahyudi. (2014). The Tensile Strength of Hooked Brick. International Journal of Engineering Trends and Technology, 18(7), 323-327. Retrieved from http://ijettjournal.org/volume-18/number7/IJETT-V18P266.pdf

Massimiliano Lucchesi. (2008). Masonry Constructions: Mechanical Models and Numerical Applications. Masonry Constructions: Mechanical Models and Numerical Applications. https://doi.org/10.1007/978-3-540-79111-9

Miha Timocevic. (2006). Earthquake Resistant Design of Masonry Building. Lobdon: Emparial Collage Press.

Priestley, M. J. N., \& Paulay, T. (1992). Seismic Design Of Reinforced Concrate and Masonry Buildings. Administrative Science Quarterly (Vol. https://doi.org/10.1080/1369801X.2015.1079 499 
Jurnal Media Komunikasi Dunia Ilmu Sipil (MoDuluS)

Volume 1, No 1, Juni 2019

Taylor. (2001). Defects in masonry walls.

Turkey. (2001). Turkey earthquake code.

for Concrete Masonry-Infilled Steel Frames. $\square \square \square \square \square \square \square \square \square \square \square \square \square \square \square \square($ Vol.

Journal of Structural Engineering,

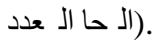

Well W. El-Dakhakhni. (2003). Three-Strut Model 9445(July),

$1-2$.

https://doi.org/10.1061/(ASCE)0733-

9445(2003)129 